\title{
癩患者の肝臟機能障碍に就て
}

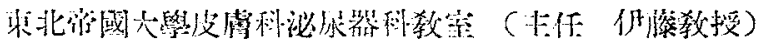

醫學士 煦 橋 通 关

緒言

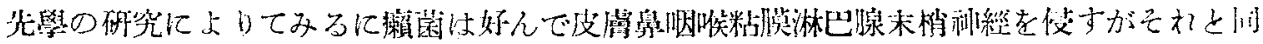

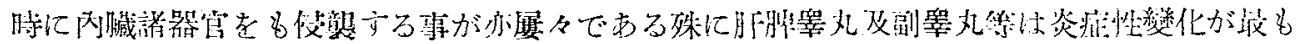
漖川である。

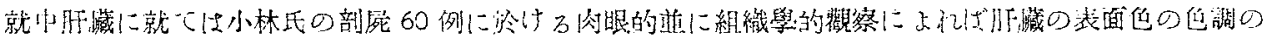

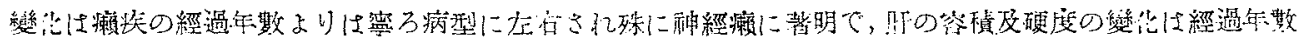

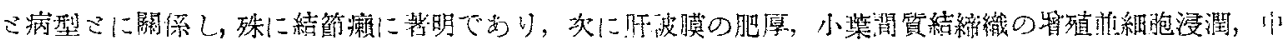

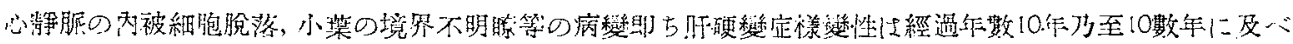

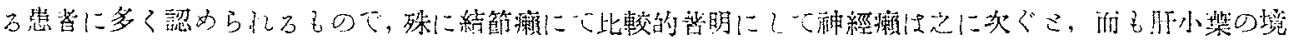

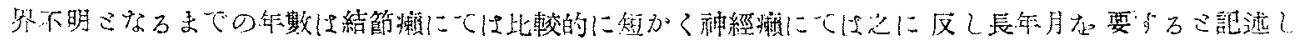

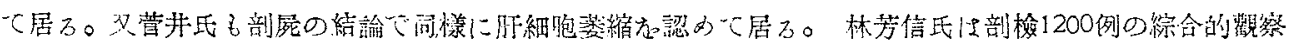

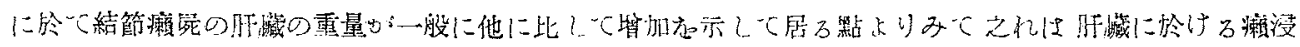

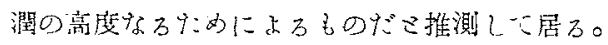

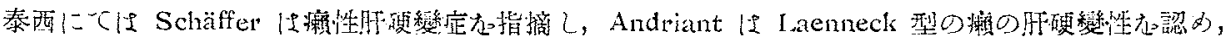

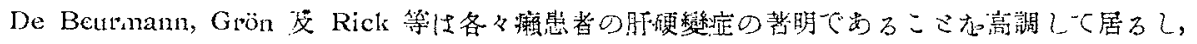

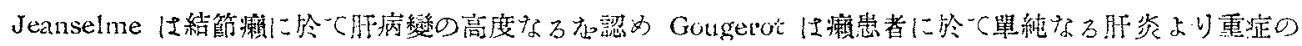

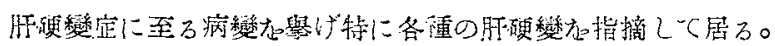

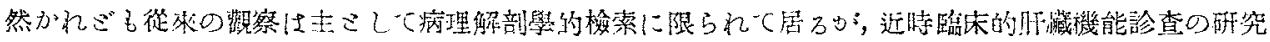

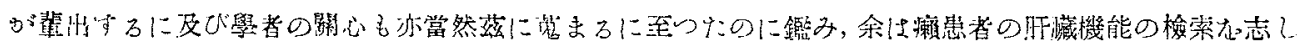

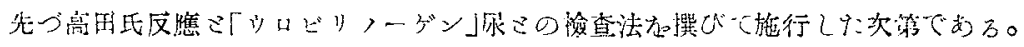

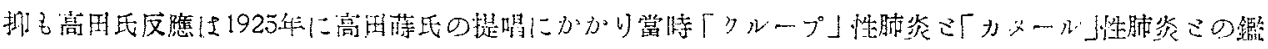

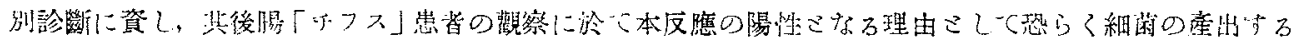

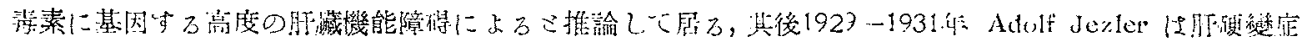

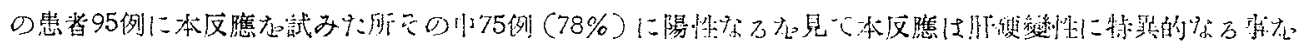

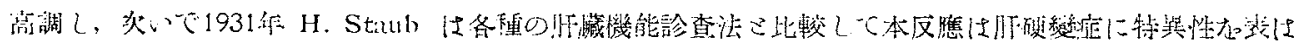

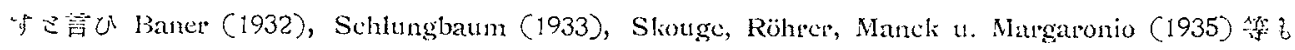

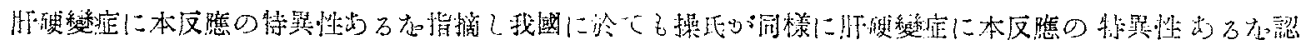




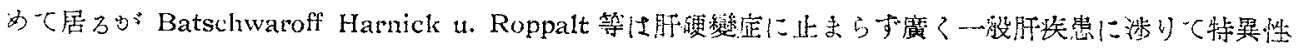

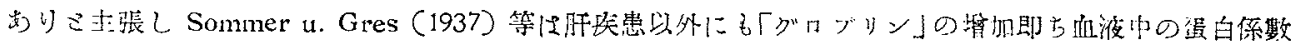

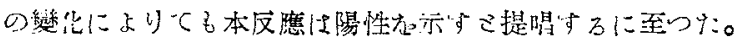

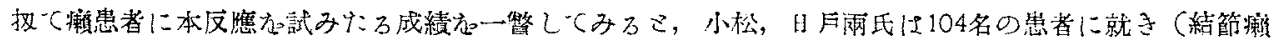

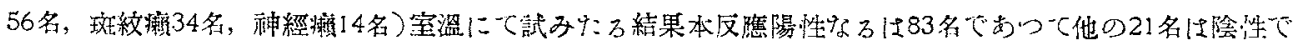

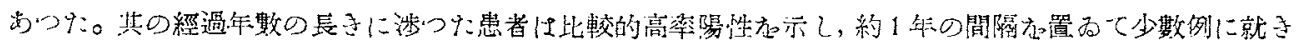

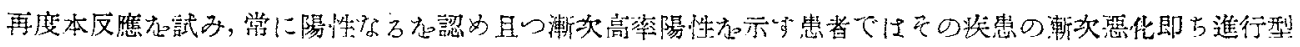

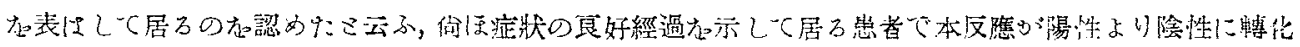

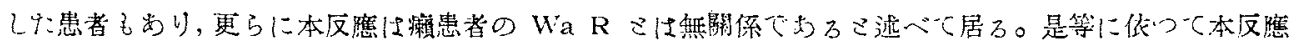

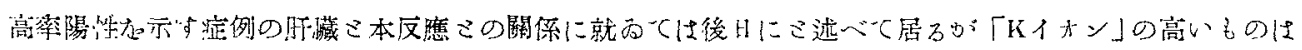

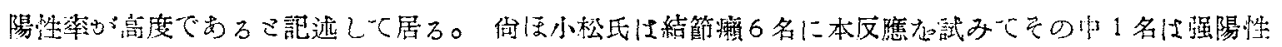

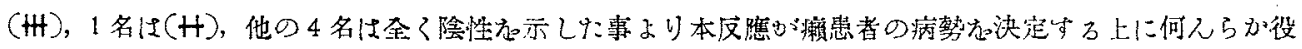

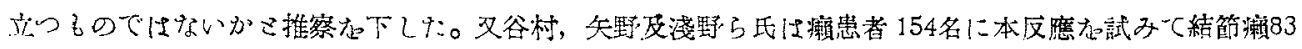

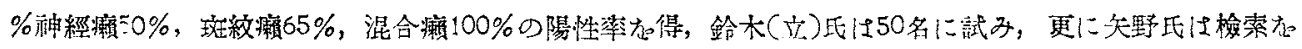

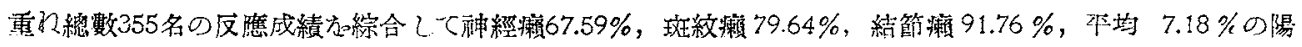

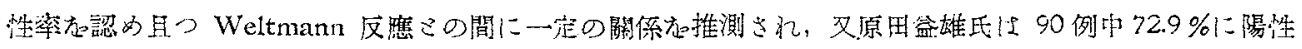

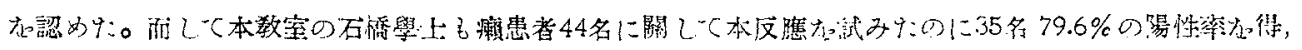

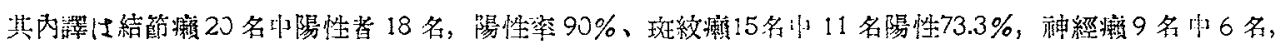

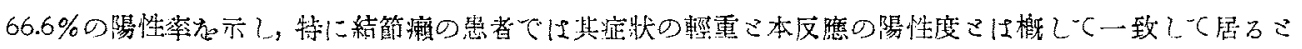

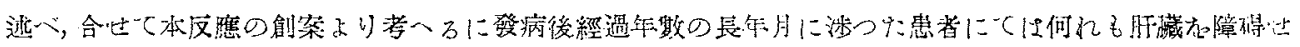

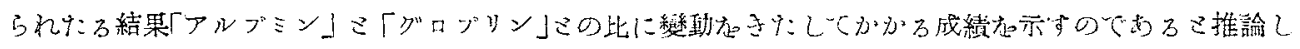

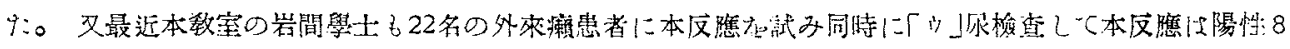

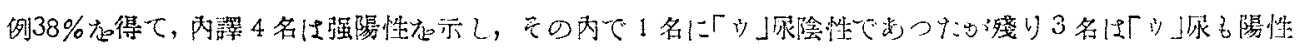

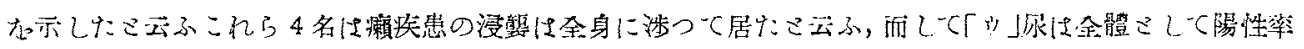

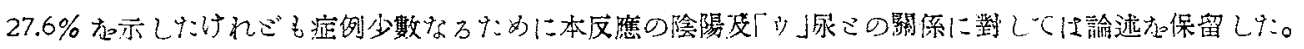

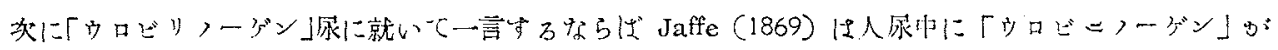

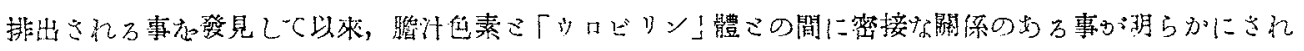

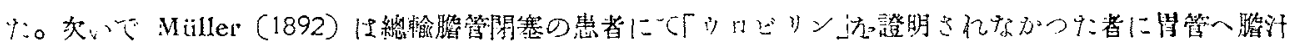

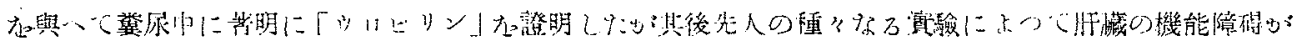

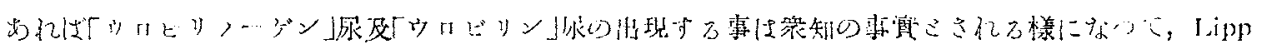

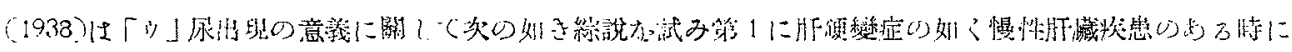

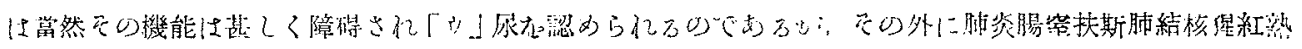

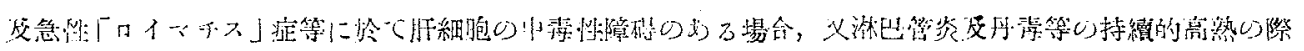

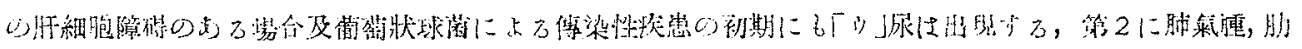




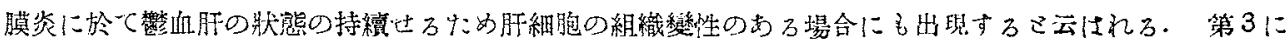

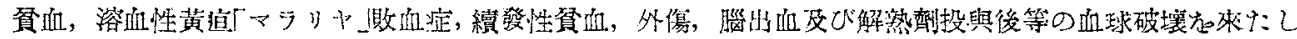

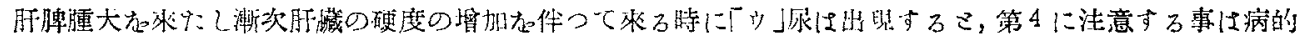

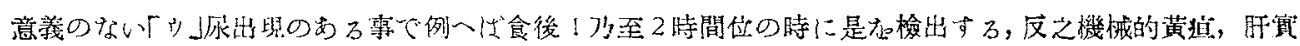

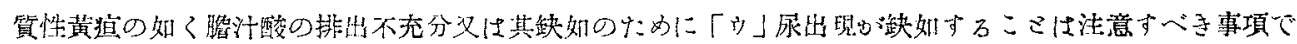

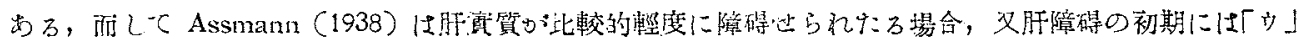

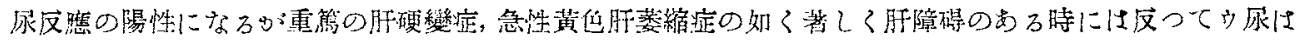

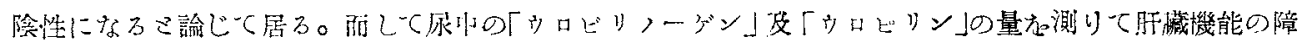

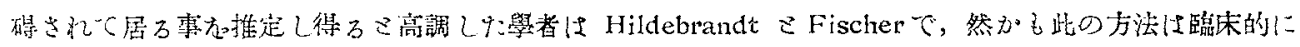

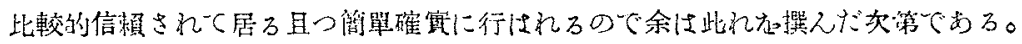

\section{II. 實驗方法及制定法}

\section{血清高时氏反應}

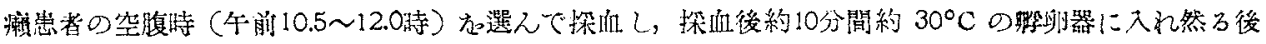

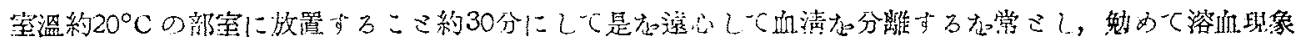

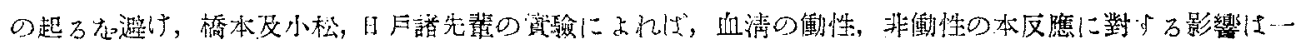

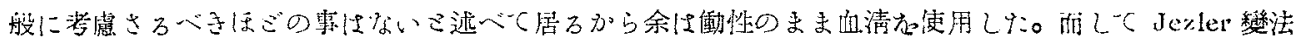

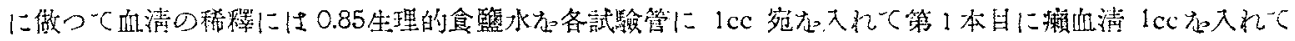

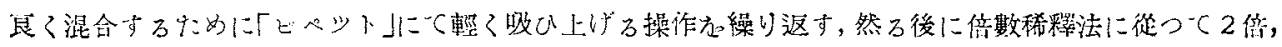

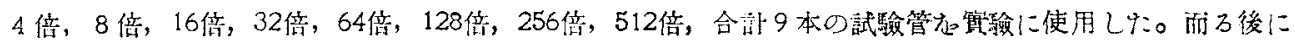

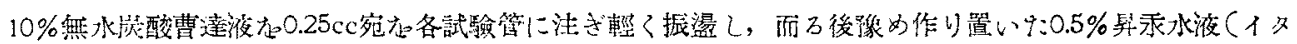

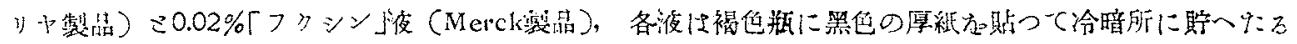

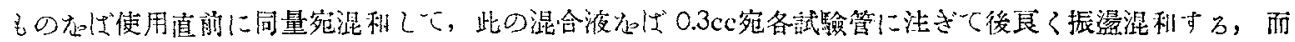

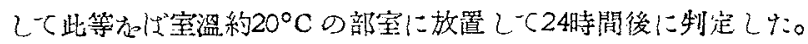

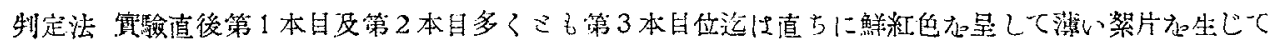

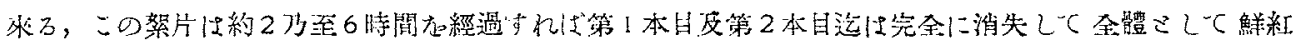

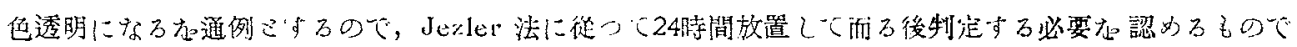

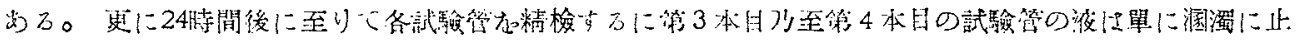

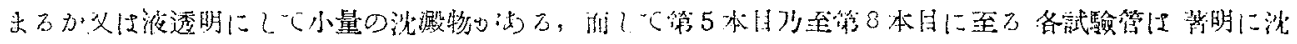

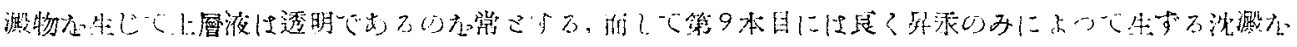

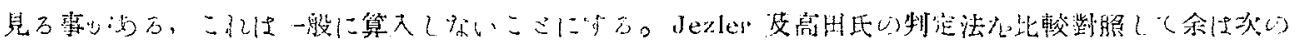

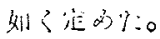

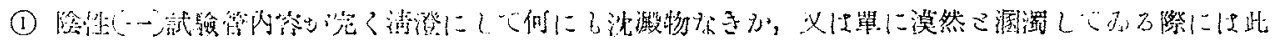
(75) 


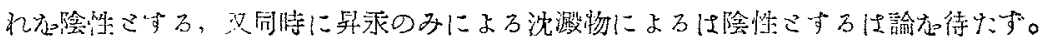

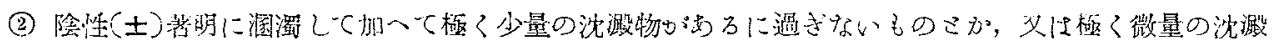

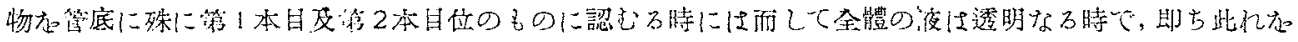

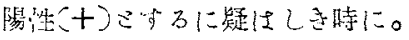

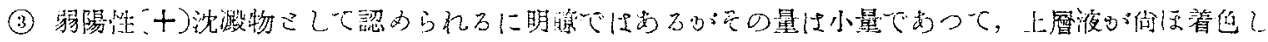

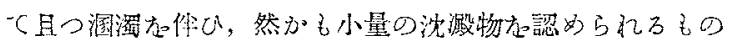

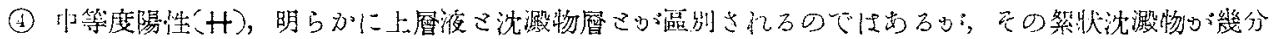

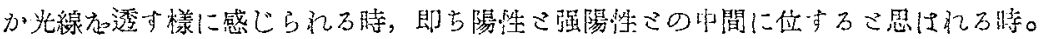

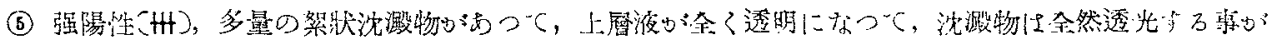

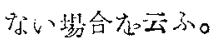

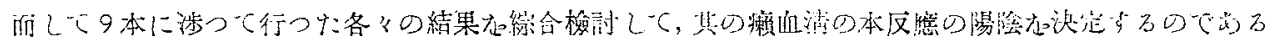

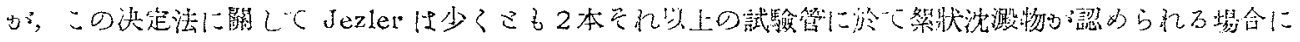

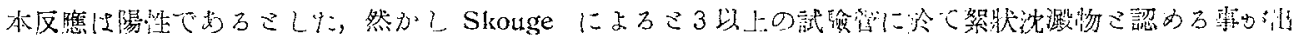

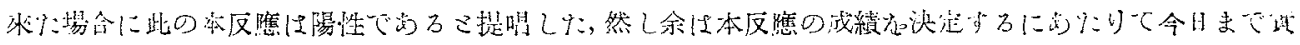

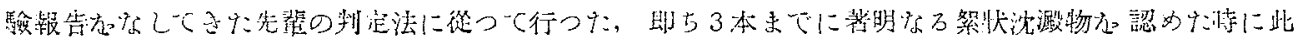

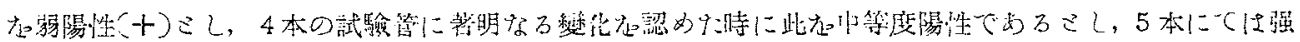

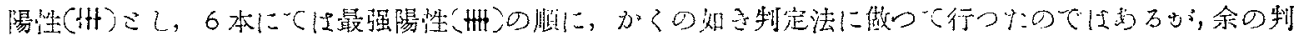

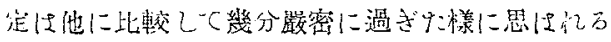

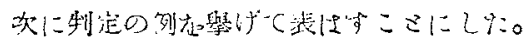

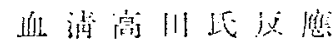

$\begin{array}{lllllllllll}\text { 例 } & 1 & 2 & 3 & 4 & 5 & 6 & 7 & 3 & 9 & \text { 刵点 } \\ 1 & - & - & - & - & \pm & + & \pm & - & - & - \\ 2 & - & - & - & - & + & + & \pm & - & - & \pm \\ 3 & - & - & - & + & + & H & + & - & - & H \\ 4 & - & - & \pm & + & + & H & + & - & - & H \\ 5 & - & - & + & + & H & H & + & - & - & H\end{array}$

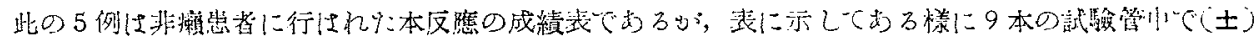

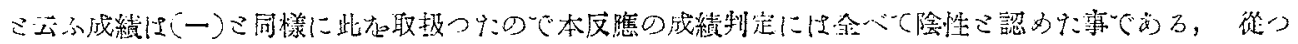

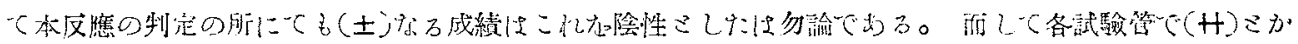

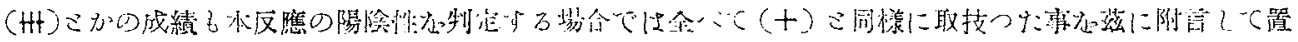
২。

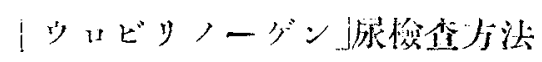

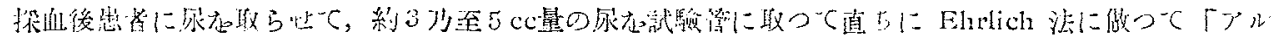




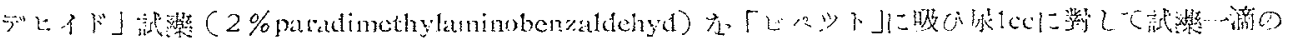

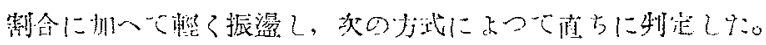

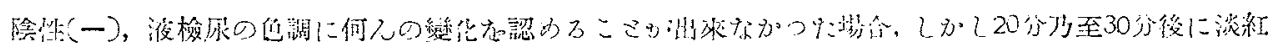

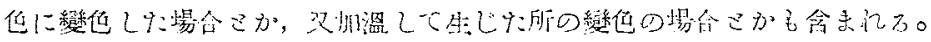

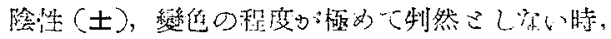

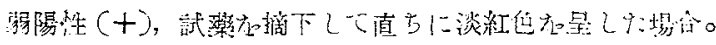

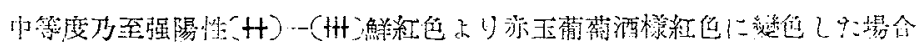

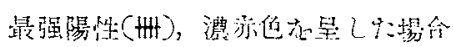

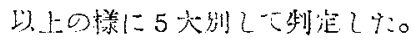

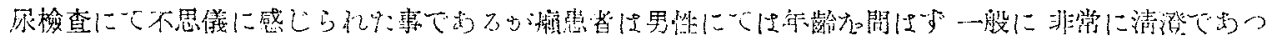

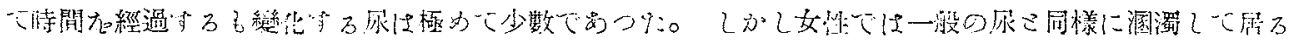

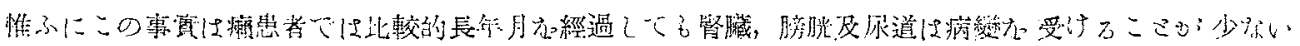

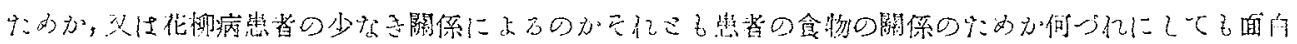

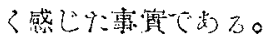

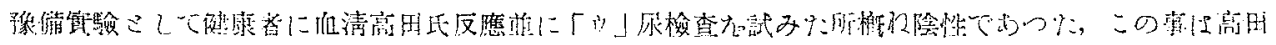

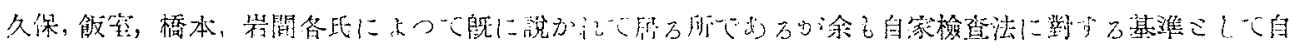

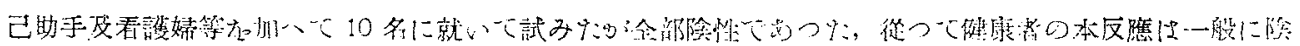

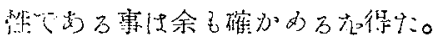

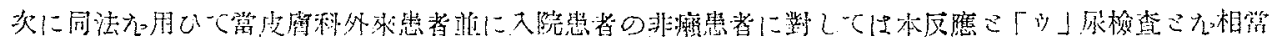

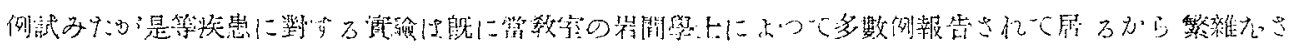

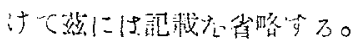

\section{III. 觀察實驗成績}

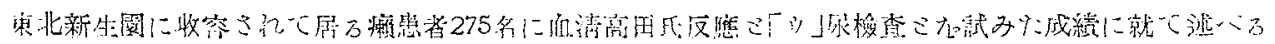

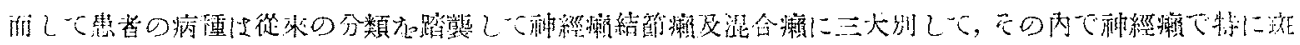

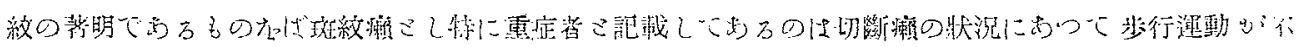

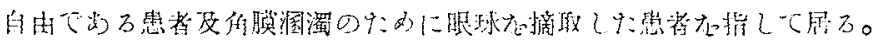

\begin{tabular}{|c|c|c|}
\hline 㐘者數 & 隄性例 & 踼性萃 \\
\hline f) 194 & 144 & $74.25 \%$ \\
\hline 81 & 51 & $62.96 \%$ \\
\hline 275 & 195 & $70.91 \%$ \\
\hline
\end{tabular}

\begin{tabular}{|c|c|c|c|}
\hline \multicolumn{4}{|c|}{ 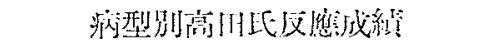 } \\
\hline 病型 & 患老数 & 陽性例 & 陽绯繁 \\
\hline 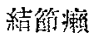 & 111 & 90 & $81.08 \%$ \\
\hline 攻紋游 & 8 & 3 & $37.50 \%$ \\
\hline 神經獬 & 75 & 50 & $65.67 \%$ \\
\hline 澀令泪 & 81 & 52 & $64.20 \%$ \\
\hline if & 275 & 195 & $70.91 \%$ \\
\hline
\end{tabular}

( 77$)$ 


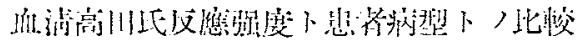

\begin{tabular}{|c|c|c|c|c|c|c|c|c|c|c|}
\hline $\begin{array}{c}\text { 反㗹强度 } \\
\text { 病型 }\end{array}$ & 性别 & - & \pm & + & $H$ & $H+$ & HAt & 隄性 & 陰性 & 合访 \\
\hline \multirow{3}{*}{ 結穊癭 } & $\hat{o}$ & 9 & 9 & 23 & 29 & 16 & 3 & 71 & 18 & 89 \\
\hline & 우 & 2 & 1 & 5 & 10 & 4 & 0 & 19 & 3 & 22 \\
\hline & tit & 11 & 10 & 28 & 39 & 20 & 3 & 90 & 21 & 111 \\
\hline \multirow{3}{*}{ 斑紋癞 } & $\hat{O}$ & 4 & 0 & 1 & 1 & 1 & 0 & 3 & 4 & 7 \\
\hline & 웅 & 1 & 0 & 0 & 0 & 0 & 0 & 0 & 1 & 1 \\
\hline & it & 5 & 0 & 1 & 1 & 1 & 0 & 3 & 5 & 8 \\
\hline \multirow{3}{*}{ 神經瀬 } & $\hat{\partial}$ & 8 & 2 & 14 & 11 & 3 & 0 & 28 & 10 & 38 \\
\hline & 9 & 9 & 6 & 13 & 9 & 0 & 0 & 22 & 15 & 37 \\
\hline & 部 & 17 & 8 & 27 & 20 & 3 & 0 & 50 & $2 \vec{J}$ & 75 \\
\hline \multirow{3}{*}{ 混合癩 } & $\hat{o}$ & 4 & 14 & 21 & 12 & 8 & 1 & 42 & 18 & 60 \\
\hline & $q$ & 4 & 7 & 2 & 6 & 2 & 0 & 10 & 11 & 21 \\
\hline & 部 & 8 & 21 & 23 & 18 & 10 & 1 & 52 & 29 & 81 \\
\hline \multirow{3}{*}{ 總 竍 } & $\hat{z}$ & 25 & 25 & 59 & 53 & 28 & 4 & 144 & 50 & 194 \\
\hline & $?$ & 16 & 11 & 20 & 25 & 6 & 0 & 51 & 30 & 81 \\
\hline & & 41 & 39 & 79 & 78 & 34 & 4 & 195 & 80 & 275 \\
\hline
\end{tabular}

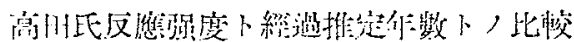

\begin{tabular}{|c|c|c|c|c|c|c|c|c|c|c|c|c|}
\hline \multirow{2}{*}{ 反鷹强度 } & \multicolumn{10}{|c|}{ 經過推 论经 数 } & \multirow{2}{*}{ Â } & \multirow{2}{*}{$\%$} \\
\hline & $0-3$ & $4-6$ & $7-9$ & $10-15$ & $16-20$ & $21-25$ & $26-30$ & $|31-35|$ & $36-40$ & $41-50 \mid$ & & \\
\hline- & 11 & 6 & 4 & 4 & 2 & 5 & 4 & 1 & 3 & 1 & 41 & $14.91 \%$ \\
\hline \pm & 14 & 3 & 4 & 10 & 1 & 1 & 0 & 2 & 2 & 2 & 39 & $10.55 \%$ \\
\hline+ & 16 & 21 & 10 & 19 & 2 & 5 & 1 & 1 & 0 & 4 & 79 & $28.73 \%$ \\
\hline+4 & 6 & 15 & 13 & 18 & 10 & 3 & 5 & 4 & 2 & 2 & 78 & $28.36 \%$ \\
\hline$H$ & 6 & 4 & 8 & 5 & 6 & 2 & 0 & 1 & 1 & 1 & 34 & $12.36 \%$ \\
\hline tht & 1 & 0 & 2 & 1 & 0 & 0 & 0 & 0 & 0 & 0 & 4 & $1.45 \%$ \\
\hline it & 54 & 49 & 41 & 57 & 21 & 16 & 10 & 9 & 8 & 10 & 275 & \\
\hline 隄秋灕 & $\begin{array}{r}53.70 \\
\%\end{array}$ & $80.41 \%$ & $\begin{array}{r}80.49 \\
\%\end{array}$ & $\begin{array}{r}75.44 \\
\%\end{array}$ & $88.71 \%$ & 62.50 & $\begin{array}{r}60.00 \\
\%\end{array}$ & 66.67 & 37.50 & 70.00 & & \\
\hline 学 均 & & $72.22 \%$ & & & $.21 \%$ & & $54 \%$ & & $94 \%$ & $\left|\begin{array}{r}70.00 \\
\%\end{array}\right|$ & & \\
\hline
\end{tabular}




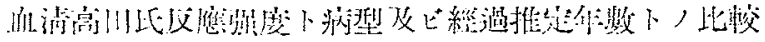

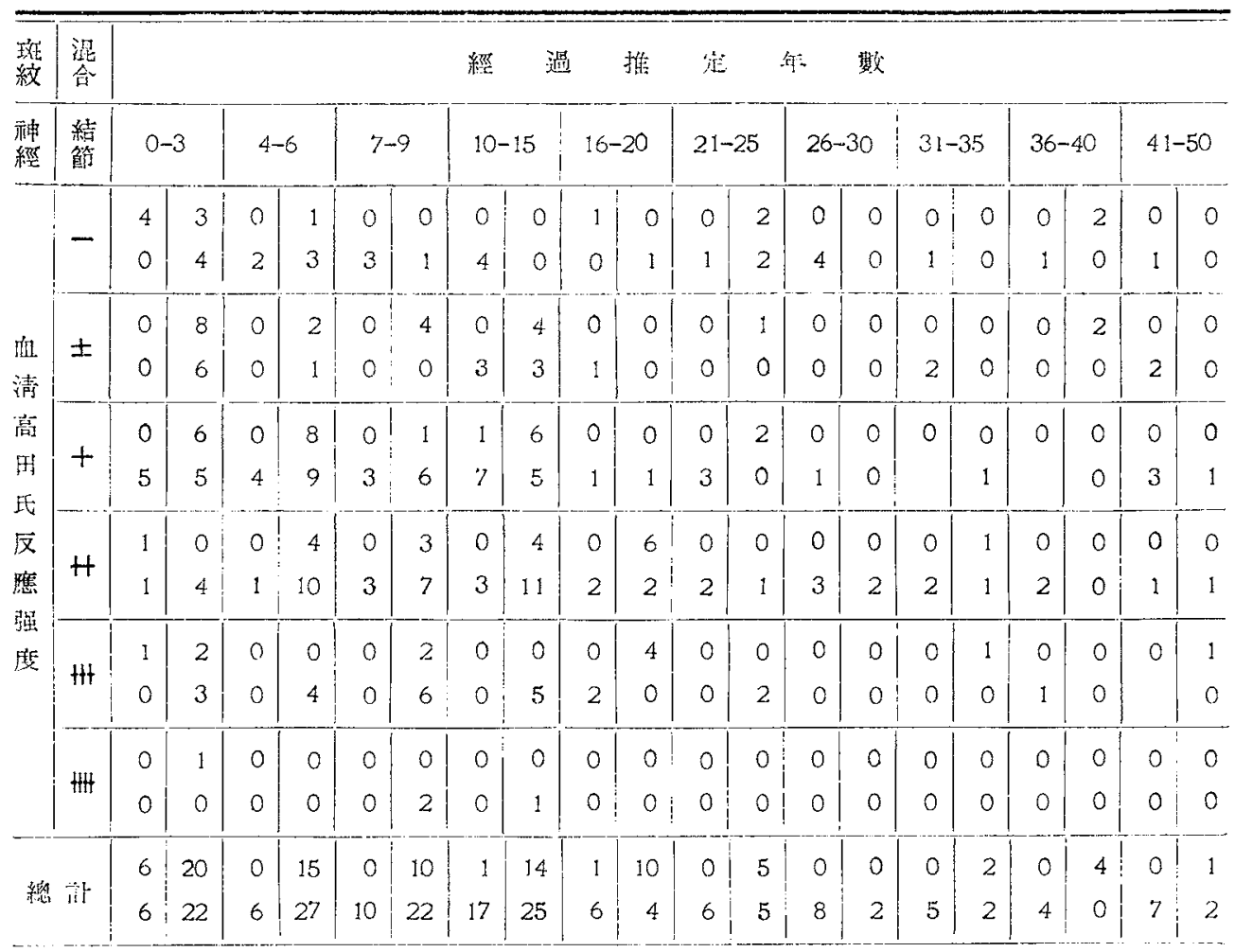

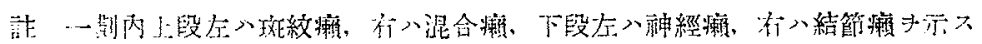

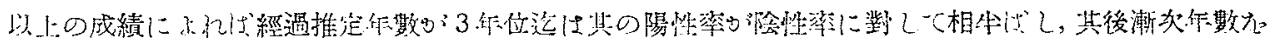

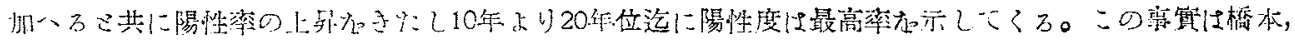

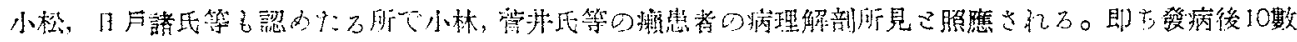

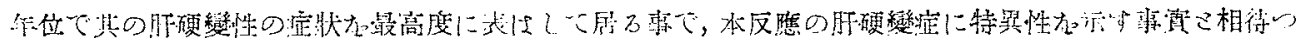

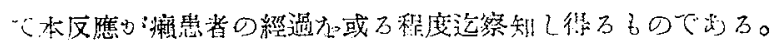

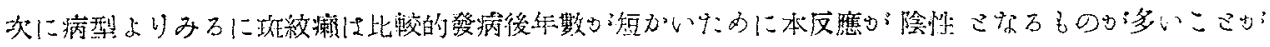

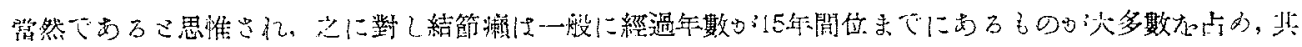

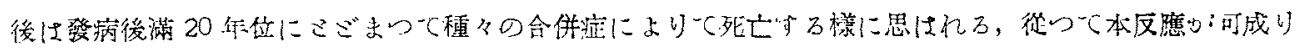

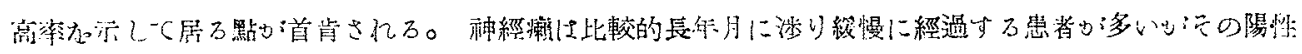

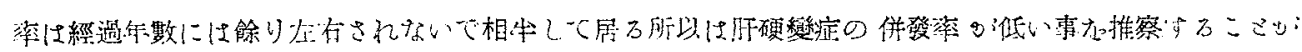
山來る。

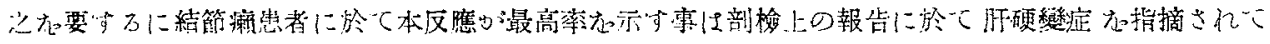

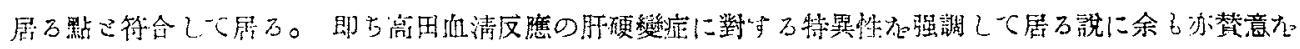




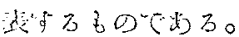

\begin{tabular}{|c|c|c|c|}
\hline 臽 & 者 & 陽科洌 & 隄性率 \\
\hline 3 & 163 & 95 & $58.89 \%$ \\
\hline P & 70 & 34 & $48.57 \%$ \\
\hline 3$\}$ & 233 & 129 & $55.41 \%$ \\
\hline
\end{tabular}

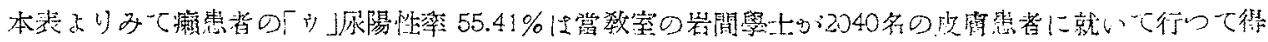

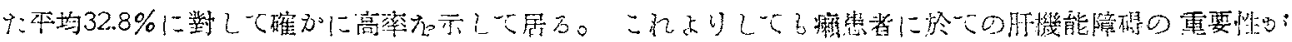
筧知是凡る。

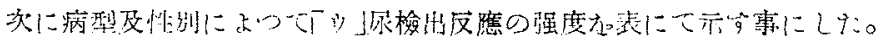

\begin{tabular}{|c|c|c|c|c|c|c|c|c|}
\hline \multirow{2}{*}{ 病型 } & \multirow{2}{*}{ 性 } & \multicolumn{6}{|c|}{ 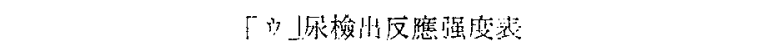 } & \multirow{2}{*}{ 總 } \\
\hline & & - & \pm & + & $H$ & $H$ & 姗 & \\
\hline \multirow{3}{*}{ 結 節 境 } & $s$ & 28 & 3 & 22 & 16 & 6 & 1 & 76 \\
\hline & 우 & 5 & 4 & 5 & 4 & 1 & 0 & 19 \\
\hline & 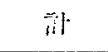 & 33 & 7 & 27 & 20 & 7 & $!$ & 95 \\
\hline \multirow{3}{*}{ 玟: 紋 瘷 } & $\delta$ & 0 & $:$ & 2 & 1 & 0 & o & 4 \\
\hline & $q$ & 1 & 0 & 0 & 0 & 0 & 0 & 1 \\
\hline & it & 1 & $!$ & 2 & 1 & 0 & 0 & 5 \\
\hline \multirow{3}{*}{ 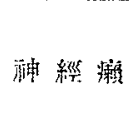 } & $\hat{\partial}$ & 10 & 2 & 13 & 6 & 3 & 0 & 34 \\
\hline & $?$ & 14 & 2 & 10 & 5 & 0 & 1 & 32 \\
\hline & it & 24 & 4 & 23 & 11 & 3 & 1 & 66 \\
\hline \multirow{3}{*}{ 混会颗 } & $\hat{o}$ & 16 & 8 & 15 & 10 & 0 & 0 & 49 \\
\hline & $?$ & 9 & 1 & 6 & 2 & 0 & 0 & 13 \\
\hline & it & 25 & 9 & 21 & 12 & 0 & 0 & 67 \\
\hline \multirow{2}{*}{ 總 } & 1 & 54 & 14 & 52 & 33 & 9 & 1 & \multirow{2}{*}{233} \\
\hline & $?$ & 29 & 7 & 21 & 11 & 1 & 1 & \\
\hline
\end{tabular}

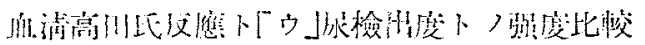

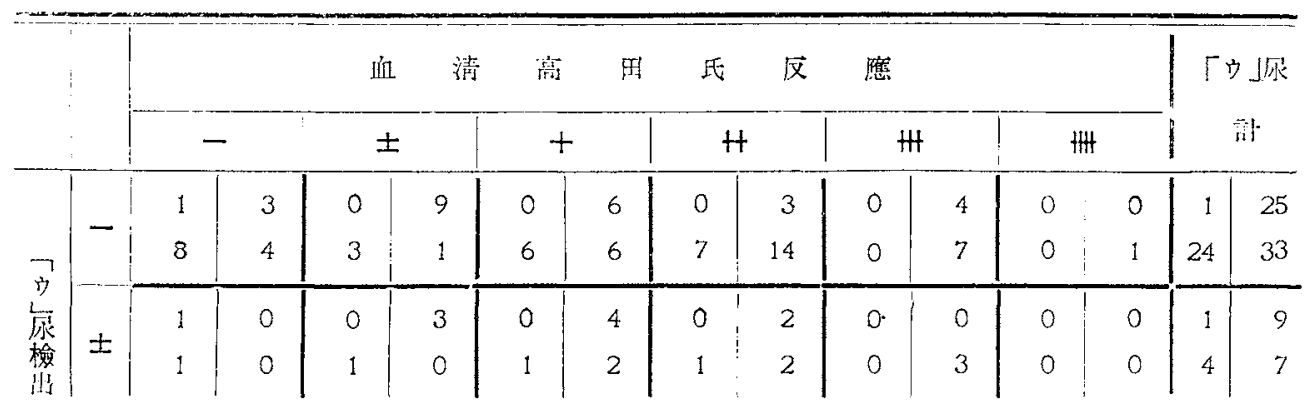




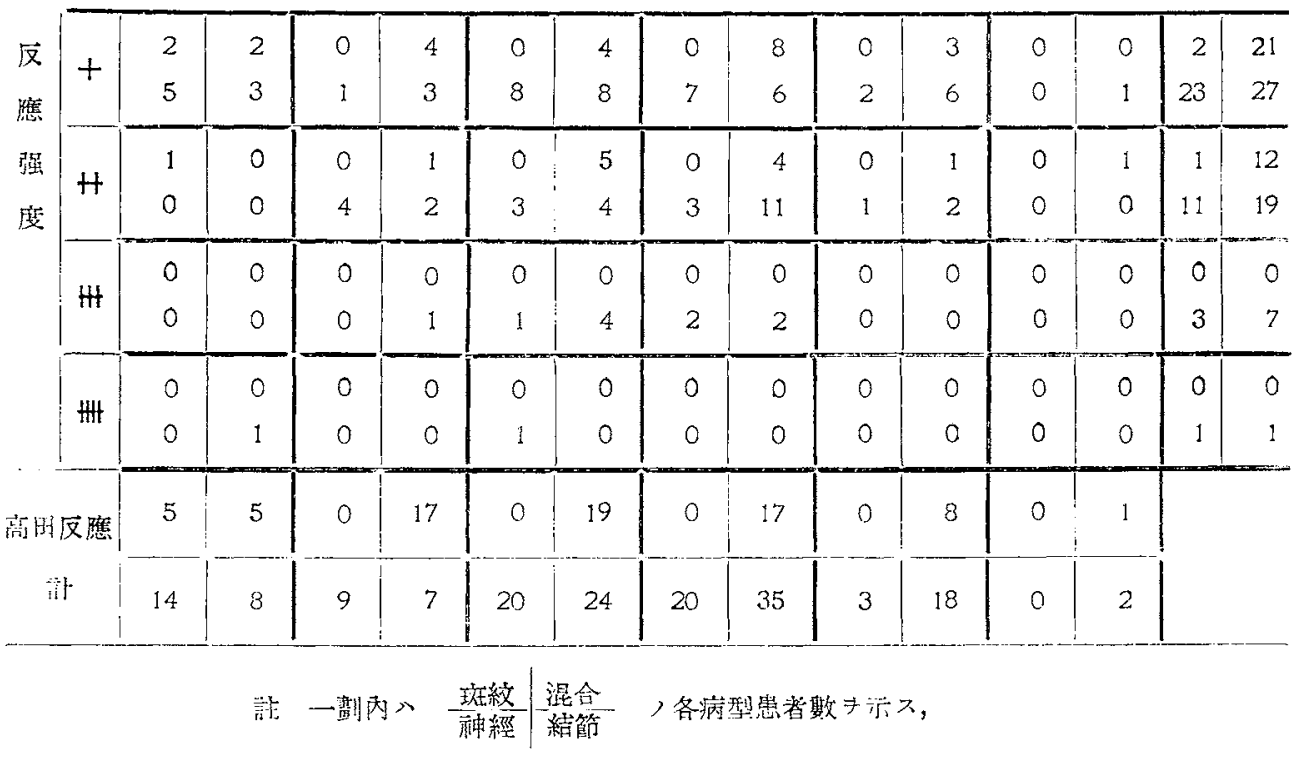

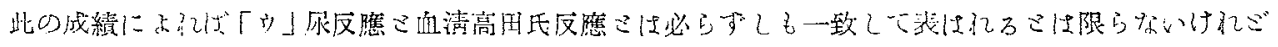

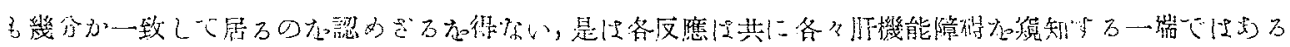

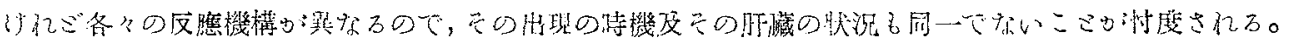

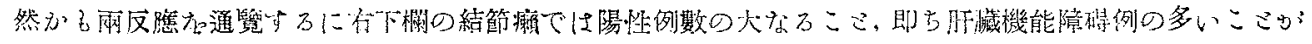
筧知㣙。

\section{IV．瀨の經過巳血清高田氏反應刑「ウ」尿の 消長ミの關係に就て}

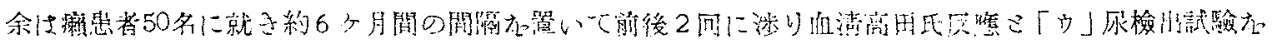

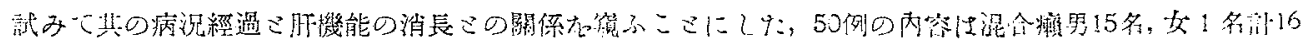

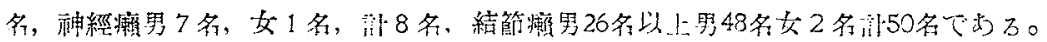

\begin{tabular}{|c|c|c|c|c|c|c|c|c|}
\hline \multirow{2}{*}{ 雷號 } & \multirow{2}{*}{ 每齡 } & \multirow{2}{*}{ 性別了 } & \multirow{2}{*}{ 病型 } & \multirow{2}{*}{$\begin{array}{l}\text { 發病 } \\
\text { 管龄 }\end{array}$} & \multicolumn{2}{|c|}{ 血清高白氏反應 } & \multirow{2}{*}{ 非病 沿 } & \multirow{2}{*}{ 「少挑 } \\
\hline & & & & & 第：同 & 第2回 & & \\
\hline 1 & 27 & s & 結節 & 10 & $H$ & tt & 㮐々進行 & $H$ \\
\hline 2 & 21 & " & & 15 & $H$ & $H$ & 進行的 & + \\
\hline 3 & 23 & $" \prime$ & & 22 & + & + & " & $H$ \\
\hline 4 & 21 & $" t$ & & 18 & - & - & 稍々萑行 & - \\
\hline 5 & 56 & $"$ & & 32 & + & $H$ & 倯々你止 & + \\
\hline 6 & 30 & $"$ & & 28 & + & + & 稍々進行 & - \\
\hline 7 & 56 & $"$ & & 53 & - & - & 俈: 战 & + \\
\hline
\end{tabular}




\begin{tabular}{|c|c|c|c|c|c|c|c|c|}
\hline \multirow{2}{*}{ 粦號 } & \multirow{2}{*}{ 胙龄会 } & \multirow{2}{*}{ 性氺 } & \multirow{2}{*}{ 病㤠 } & \multirow{2}{*}{ 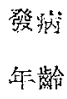 } & \multicolumn{2}{|c|}{ 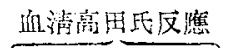 } & \multirow{2}{*}{ N! 满沉 } & \multirow{2}{*}{ 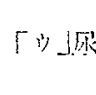 } \\
\hline & & & & & 第 1 回 & 第2 问 & & \\
\hline 46 & 25 & $" 1$ & 州緤 & 20 & - & + & 倧 & - \\
\hline 47 & 41 & $" \prime$ & & 19 & - & $H$ & 㮐進行 & + \\
\hline 48 & 42 & $"$ & & 35 & $H H$ & $H$ & 倍 & - \\
\hline 49 & 33 & $" \prime$ & & 23 & - & - & $" \prime$ & \\
\hline 50 & 55 & i & & 28 & - & H & 稳々進行 & - \\
\hline
\end{tabular}

\begin{tabular}{|c|c|c|c|c|c|c|c|}
\hline & \multicolumn{5}{|c|}{ 第 1 回目血清高时氏反應 } & \\
\hline & & - & \pm & + & $H$ & HH & m \\
\hline 第 & - & 8 & 0 & 0 & 1 & 1 & \\
\hline 回 & \pm & 0 & 0 & 0 & 0 & 0 & 0 \\
\hline 血 & + & 9 & 0 & 7 & 6 & 0 & 0 \\
\hline 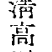 & $H$ & 4 & 0 & 4 & 3 & 1 & 1 \\
\hline 至 & $\mathrm{HH}$ & 3 & 0 & 0 & 1 & 1 & 0 \\
\hline & 册t & 0 & 0 & 0 & 0 & 0 & 0 \\
\hline
\end{tabular}

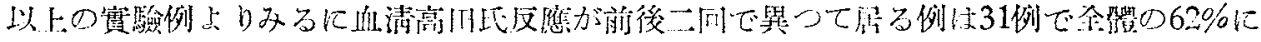

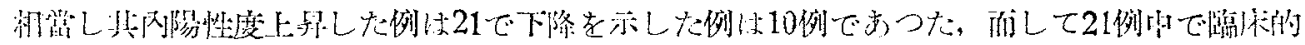

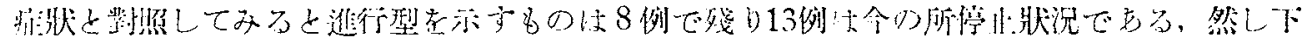

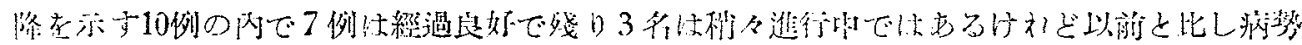

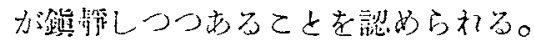

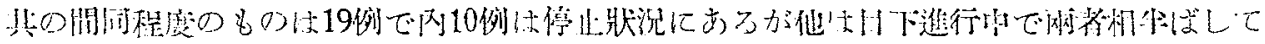

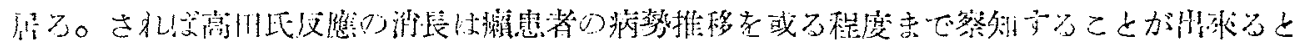

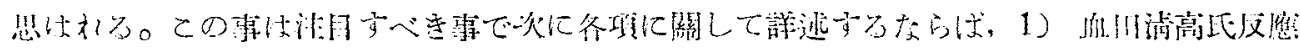

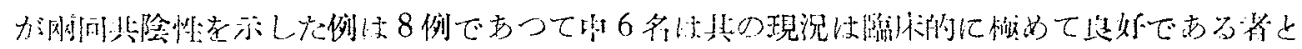

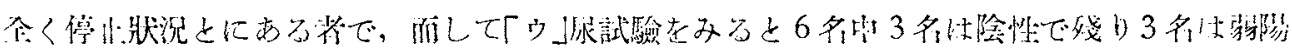

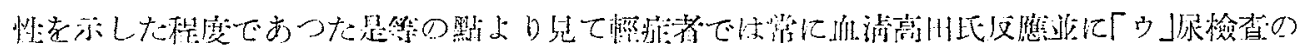

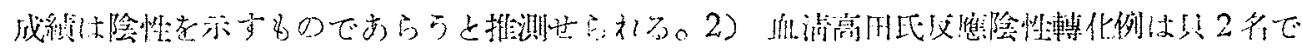

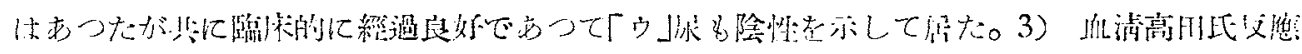

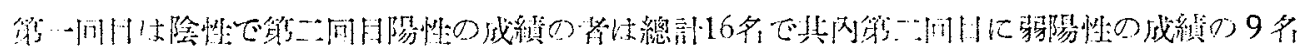

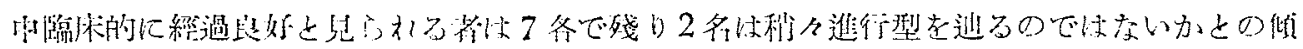

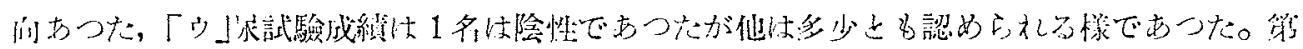

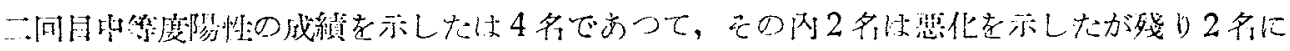

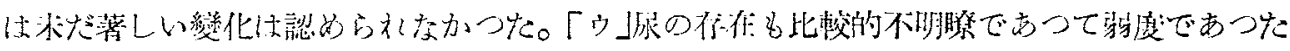




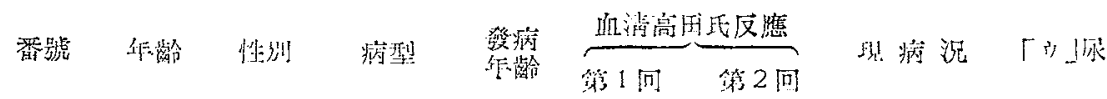

\begin{tabular}{|c|c|c|c|c|c|c|c|c|}
\hline 8 & 33 & $" 1$ & 結節 & 22 & + & + & 倍 & + \\
\hline 9 & 23 & $"$ & & 18 & + & $H$ & 進行山 & - \\
\hline 10 & 25 & $"$ & & 16 & - & + & 侮 止 & $H$ \\
\hline 11 & 47 & $" 1$ & & 28 & - & $t$ & $" 1$ & - \\
\hline 12 & 22 & $"$ & & 16 & + & + & 是 好 & - \\
\hline 13 & 28 & " & & 24 & - & - & 㐿 & - \\
\hline 14 & 26 & " & & 16 & $H$ & + & 垦型 & + \\
\hline 15 & 23 & $"$ & & 20 & - & - & " & + \\
\hline 16 & 38 & $"$ & & 26 & $H$ & $\mathrm{Ht}$ & 佔 & - \\
\hline 17 & 25 & $"$ & & 15 & $H H$ & HH & $"$ & + \\
\hline 18 & 22 & $"$ & & 15 & + & + & 進 行 & - \\
\hline 19 & 25 & $"$ & & 18 & $H$ & - & 倍 止: & - \\
\hline 20 & 43 & $" 1$ & & 21 & - & - & 㸧々進行 & - \\
\hline 21 & 67 & $" 1$ & & 58 & t+ & + & " & - \\
\hline 22 & 28 & "l & & 21 & - & tHt & 稍々你止 & + \\
\hline 23 & 28 & $" l$ & & 23 & - & + & 㮐々進行 & \pm \\
\hline 24 & 35 & " & & 25 & $H$ & + & 稍々㯪此 & + \\
\hline 25 & 51 & $" 1$ & & 25 & + & $H$ & 秒々蓬行 & $\mathrm{HH}$ \\
\hline 26 & 40 & $" l$ & & 36 & - & + & 信 止. & - \\
\hline 27 & 27 & $"$ & 混命 & 19 & - & - & 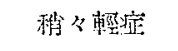 & + \\
\hline 28 & 23 & $"$ & & 18 & 册 & $H$ & 进行地是 & - \\
\hline 29 & 39 & $"$ & & 13 & $H$ & + & 俈 此 & $H$ \\
\hline 30 & 30 & $" 1$ & & 19 & + & + & $"$ & \pm \\
\hline 31 & 41 & $" l$ & & 28 & - & + & "1 & $H$ \\
\hline 32 & 24 & $" l$ & & 20 & $\mathrm{HH}$ & - & "I & - \\
\hline 33 & 37 & " & & 30 & $H$ & + & 稍々進行中良 & tt \\
\hline 34 & 48 & " & & 21 & $H$ & $H$ & 稚々溡行 & $H t$ \\
\hline 35 & 24 & $" \prime$ & & 15 & $H$ & + & 儌 止. & + \\
\hline 36 & 47 & "l & & 36 & + & + & " & H \\
\hline 37 & 33 & $" t$ & & 23 & - & HH & 潐行 & - \\
\hline 38 & 38 & $"$ & & 21 & - & $\mathrm{Ht}$ & $"$ & + \\
\hline 39 & 28 & $" \prime$ & & 16 & - & + & 侜 此 & + \\
\hline 40 & 28 & "l & & 16 & + & $H$ & 秒進行 & + \\
\hline 41 & 65 & $"$ & & 16 & - & $H$ & 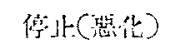 & + \\
\hline 42 & 45 & ? & & 41 & - & + & 程》衔止 & $H$ \\
\hline 43 & 31 & 3 & 神舟經 & 25 & - & + & $"$ & \pm \\
\hline 44 & 42 & $" 1$ & & 21 & - & + & 科摊行 & + \\
\hline 45 & 45 & " & & 34 & - & - & it. & $H$ \\
\hline
\end{tabular}




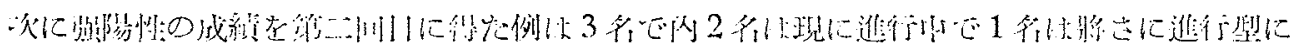

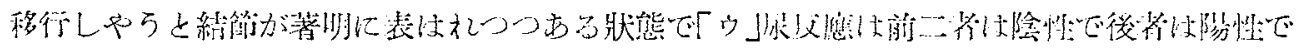

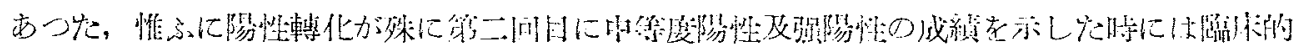

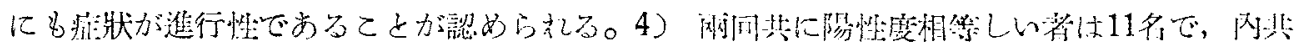

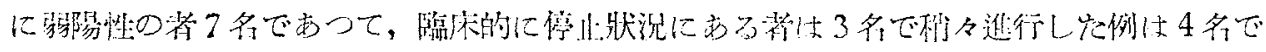

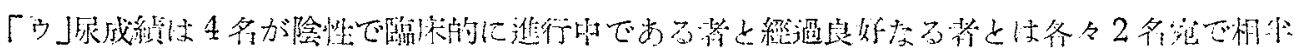

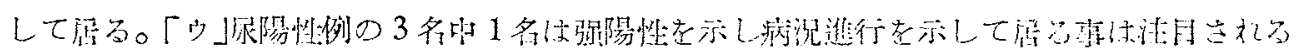

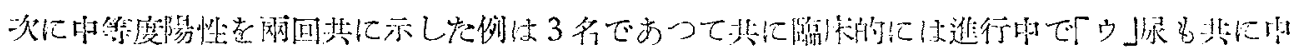

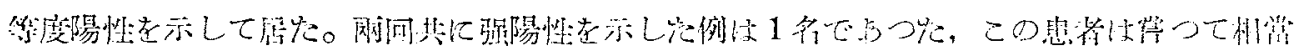

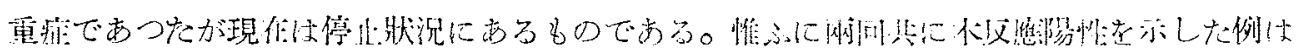

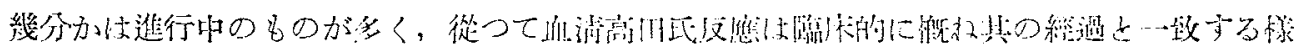

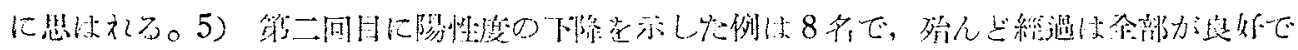

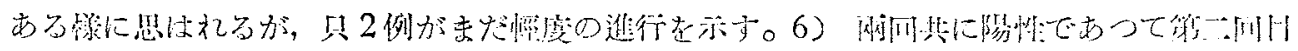

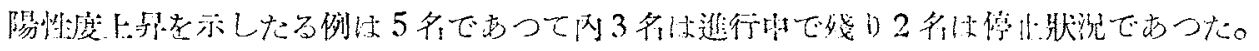

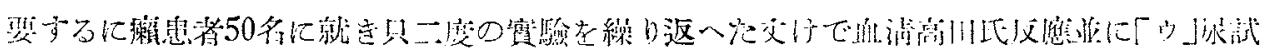

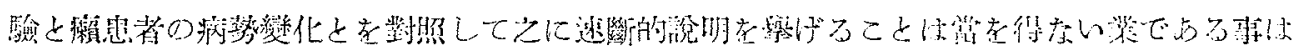

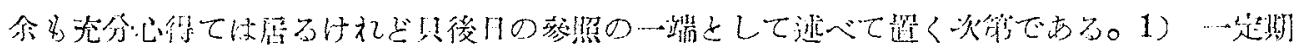

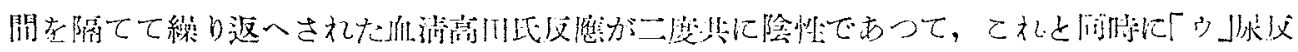

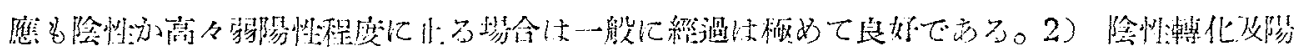

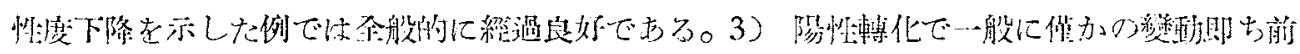

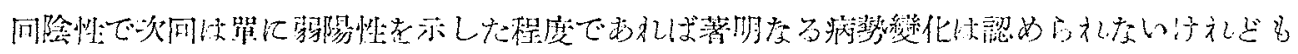

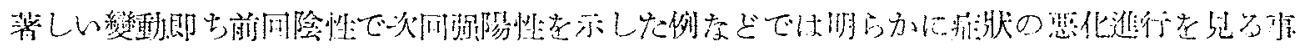

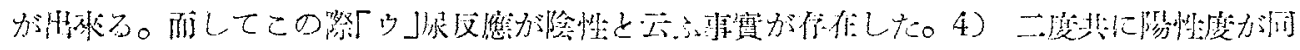

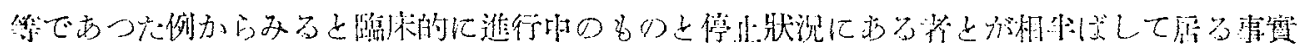

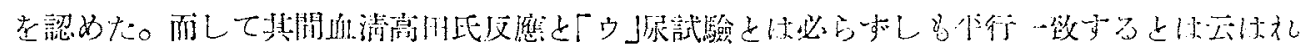

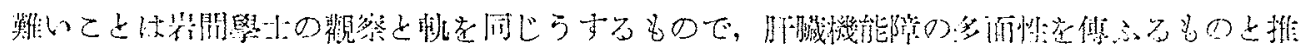
然され多。

\section{V. 結 論}

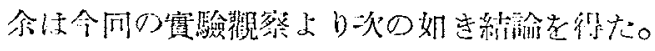

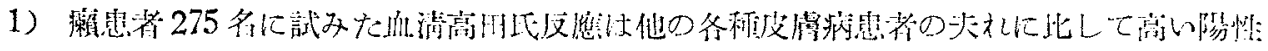


离离示す。

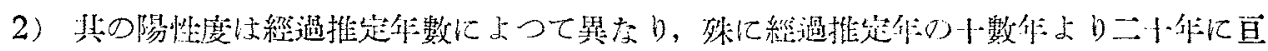

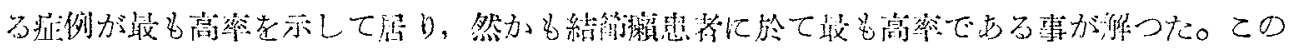

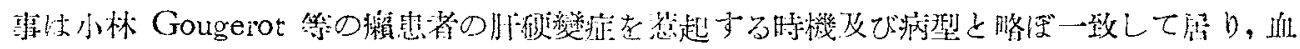

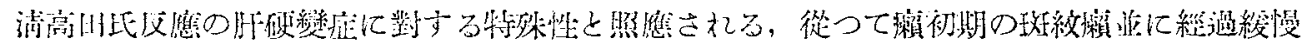

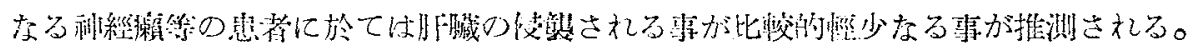

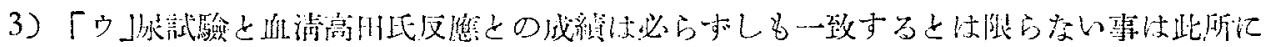

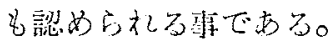

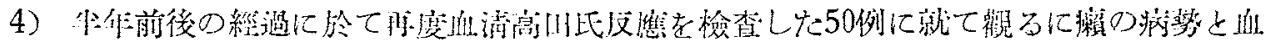

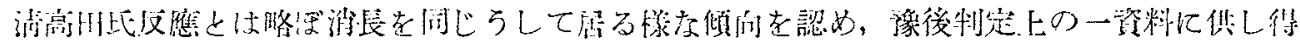
ると琶は礼。

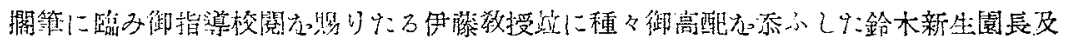

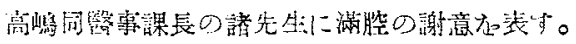

\section{文献}

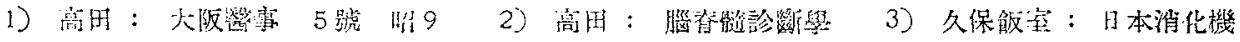

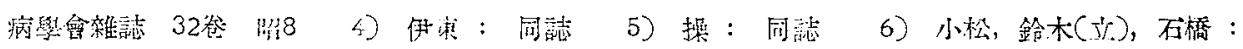

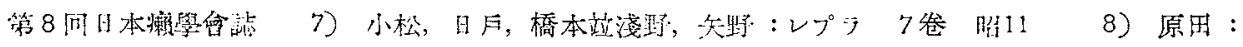

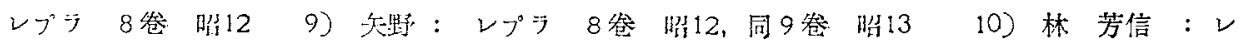

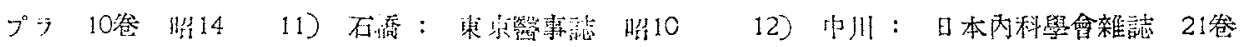

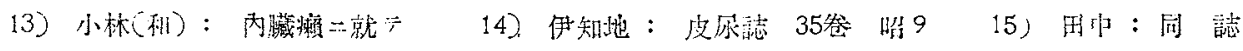

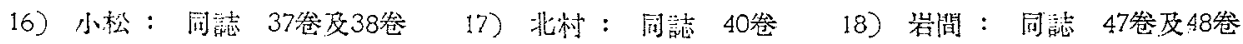

19) Gougerot : Nulv. Prati. Derm. III (1936) 20) Jeanselme : La lépre (1934) 21) Je ler : Beitrag zur funktionelle Leberdingnostik (1929) $\quad$ 22) Klingmïller : Jadassohn's Handbuch $(\mathrm{X} / 2)$ 23) Taka'a : Über dic Takata-reaktion in Blut (1925)

(昭利16年4月20日受稿) 


\title{
EINE UNTERSUCHUNG MIT DER TAKATA-REAKTION UND DER UROBII.INOGENURIEPROBE BEI LEPRAKRANKEN.
}

\author{
Von \\ Dr. Michio Takahasi. \\ [Aus der Hautklinitk der Kaiserlichen Tōhoku- Llniversität zu Sendai \\ (Vorstand: Prot. Dr. M. Itō)]
}

Die Tanaka-Reaktion wurde von Dr Takata also Liquorreaktion sowie als Differentialdiagnostik zwischen katarrhalischer und cruppöser Pneumonie angegeben, und von Jezler u. Staub als spezifische Diagnostik der Leberzirrhose empfohlen. Seitdem wird diese Reaktion für die Leberfunktionsprüfung angewandt. Jaffe machte darauf aufmerksam, dass Urobilin- und Urobilinogen-Reichtum des Harns zu den Symptomen der Leberfunktionsstörung gehört.

Bei Leprakranken stellt sich häufig Leberschädigung ein, insbesondere Leberzirrhose. Daraufhin bediente sich Verf. der Takata-Reaktion und der Urobilinogenurieprobe bei 275 Fällen von Aussatz.

Die Takata-Reaktion zeigt in 195 von 275 Aussatz-Fällen, also zu 70.9\%, ein positives Resultat; ebenso bei 90 von 111 Lepra tuberosa, also $81.08 \%$; bei 52 von 81 Lepra mixta, also $64.20 \%$; bei 50 von 72 Lepra nervosa, also $66.67 \%$ und bei 3 von 8 Lepra maculosa, also 37,50\%. Bei 50 Leprakranken konnte der Verf. eine gewisse Schwankung der Takata-Reaktion mehr oder weniger parallel mit dem klinischen Verlauf beobachten.

Die Urobilinogenurieprobe fiel bei 129 von 233 Leprakranken, d. h. $55.41 \%$ positiv aus.

Diese Ergebnisse können wohl als schlagender Beweis gelten für eine einwandfreie Diagnose der Leberschädigung insbesondere der Leberzirrhose bei Leprakranken. 